\title{
VIVENDO O TEMPO ATMOSFÉRICO: O YOUTUBE COMO FERRAMENTA PEDAGÓGICA NO ENSINO DE GEOGRAFIA
}

\author{
LIVING THE ATMOSPHERIC WEATHER: YOUTUBE AS A \\ PEDAGOGICAL TOOL IN GEOGRAPHY TEACHING
}

\author{
Iara Regina Nocentini André \\ Doutora, Universidade de Brasília - UnB \\ Brasília, DF - Brasil \\ iaranocentini@gmail.com \\ Dilberto Lacerda Santos \\ Professor Titular, Universidade de Brasília - UnB \\ Brasília, DF - Brasil \\ gilberto.lacerda.santos@gmail.com
}

\begin{abstract}
Resumo: O projeto Pelos caminhos de Darwin deu origem a um portal intitulado O Diário do Bigou e a um livro digital com diversas ligações com a plataforma de distribuição de vídeos YouTube, a fim de levar o leitor do livro digital a se aproximar de forma mais efetiva dos fenômenos climáticos descritos por Darwin em seu diário, através da série Vivendo o Tempo Atmosférico. Para se verificar a pertinência do uso do YouTube como ferramenta pedagógica no ensino de Geografia, os vídeos foram avaliados por uma turma de Licenciatura em Pedagogia da Faculdade de Educação da Universidade de Brasília, no contexto da disciplina Educação, Tecnologias e Comunicação. Neste artigo são avaliadas as impressões destes atores que demonstraram excelente aceitação do material didático.
\end{abstract}

Palavras-chave: Charles Darwin. Youtube. Ensino de geografia. Divulgação científica.

Abstract: The project Pelos Caminhos de Darwin has given rise to a portal titled The Bigou's Diary and a digital book using the YouTube digital video distribution platform as an educational device in order to get its reader to approach most effectivelly the climatic phenomena described by Darwin in his diary, through the serie named Living Atmospheric Weather. In order to be aware of this pedagogical possibility, the videos were evaluated by a group of pedagogy students of the Faculty of Education of the University of Brasilia, in the context of a course about Education, Technologies and Communication. In this article we evaluated the impressions of these actors who demonstrated excellent acceptance of didactic material.

Keywords: Charles Darwin. YouTube. Didactics of geography. Scientific divulgation.

\section{Para citar - (ABNT NBR 6023:2018)}

ANDRÉ, Iara Regina Nocentini; SANTOS, Gilberto Lacerda. Vivendo o tempo atmosférico: o YouTube como ferramenta pedagógica no ensino de geografia. Eccos - Revista Cientifica, São Paulo, n. 55, p. 1-12, e8354, out./dez. 2020. Disponível em: https://doi.org/10.5585/eccos.n55.8354. 


\section{Introdução}

O projeto Pelos Caminhos de Darwin consistiu em um empreendimento de engenharia de mídias educativas destinadas à promoção da divulgação científica acerca da Teoria da Evolução das Espécies, de Charles Darwin. Concebido e desenvolvido por uma equipe de pesquisadores de diferentes campos disciplinares, o projeto foi delimitado sob a forma de uma pesquisa ação que buscou disponibilizar um material didático inovador, tanto em termos de processo de desenvolvimento quanto em termos de produto desenvolvido. Esse ambicioso projeto de engenharia de mídias para a educação, que contou com apoio financeiro do Ministério das Cidades, do Conselho Nacional de Pesquisas (CNPq), da Fundação de Apoio à Pesquisa do Distrito Federal (FAPDF), da Marinha do Brasil e da Universidade de Brasília $(\mathrm{UnB})$, gerou dois produtos principais, ambos concebidos por meio da abordagem dos Métodos Ágeis de engenharia de softwares (MOTTA et al., 2017a): um portal de contextualização e de apresentação do projeto, intitulado $O$ Diário do Bigou ${ }^{1}$, e um livro digital, em que são retomados os caminhos de Darwin para a elaboração de sua revolucionária teoria (MOTTA et al., 2017b).

Desenvolvido pela equipe do Laboratório Ábaco de Pesquisas Interdisciplinares sobre Tecnologias e Educação, da Faculdade de Educação da Universidade de Brasília, o portal $O$ Dário do Bigou disponibiliza uma apresentação geral do projeto, sua contextualização pedagógica para exploração didática do conteúdo, possibilidades de aprofundamento a respeito da Teoria da Evolução das Espécies, além dos bastidores dos trabalhos e das viagens da equipe, seguindo os principais passos de Darwin pela América do Sul. O objetivo do portal é trazer recursos didáticos e informações relevantes aos professores e alunos do ensino fundamental e médio, para auxiliar no processo de aprendizagem em sala de aula, mas também enfatizar o prazer em pesquisar e desmistificar o jovem naturalista que, na época da viagem do Beagle, tinha cerca de 20 anos de idade. As viagens do Bigou foram realizadas em Brasília, nas Ilhas Galápagos, no Rio de Janeiro, em Fortaleza, em Fernando de Noronha, no Arquipélago de São Pedro e São Paulo, na Terra do Fogo e na Patagônia. Esse conjunto de recursos didáticos consiste em um Ambiente Educativo Multimediatizado, conceito derivado das investigações de Lacerda Santos (1998), em busca da proposição de uma metodologia holística para a engenharia

\footnotetext{
${ }^{1}$ A equipe de pesquisadores responsável pela concepção e pelo desenvolvimento do projeto foi constituída por três especialistas em Informática Educativa, uma bióloga, dois geógrafos e um fotógrafo-historiador. A equipe se autodenominou "Bando de Investigadores com Garra e Ousadia", de modo a dar forma ao acrônimo Bigou e a intitular os registros de suas pesquisas de campo de Diário do Bigou, em analogia ao Diário do Beagle, elaborado por Charles Darwin para descrever suas próprias viagens e observações.
} 
de softwares educativos. A Figura 1 apresenta a interface principal do portal de contextualização do projeto:

Figura 1 - Interface principal do portal de contextualização do projeto Pelos caminhos de Darwin

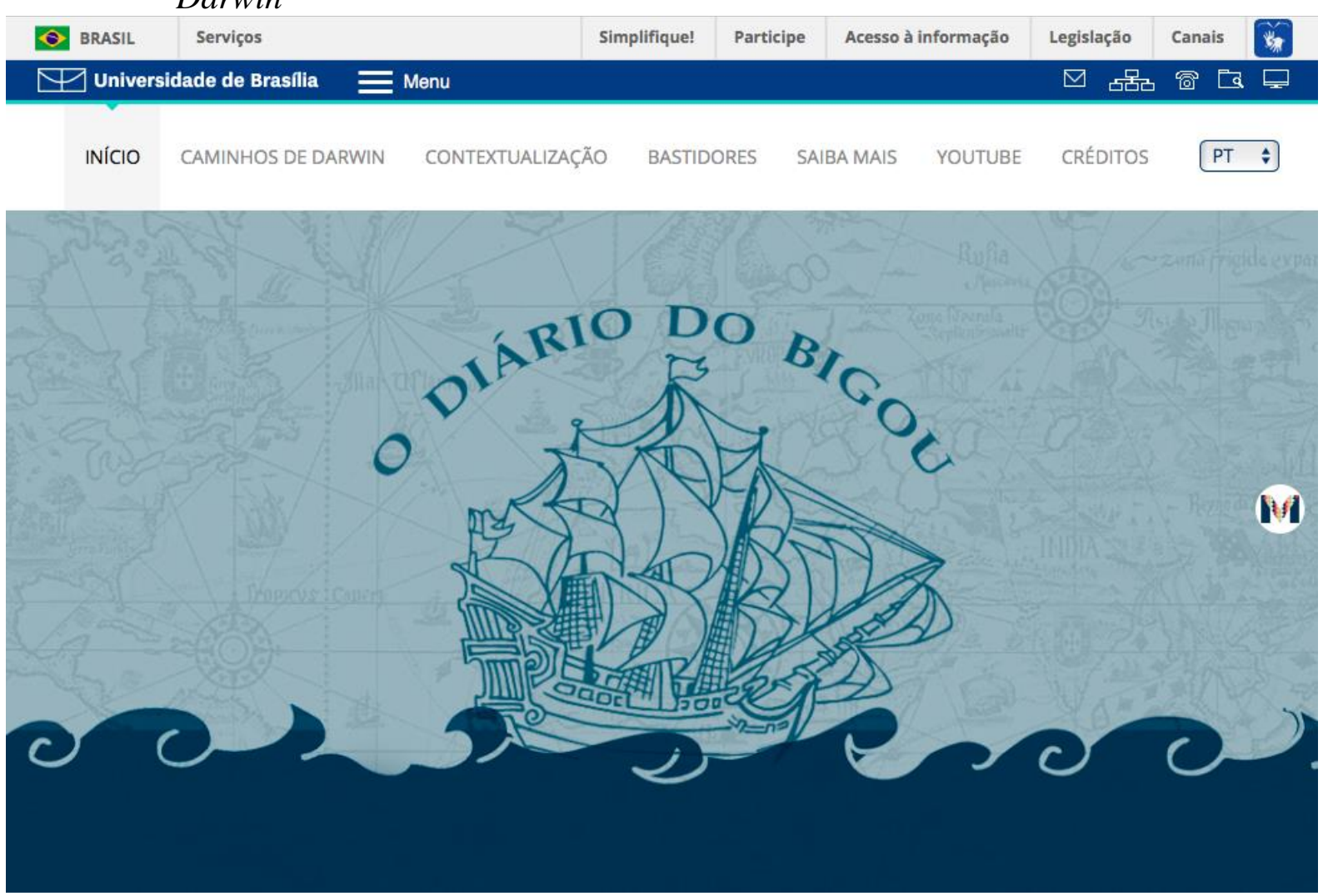

Fonte: Motta et al. (2017a).

O livro digital, ao qual se tem acesso por meio do portal de contextualização, apresenta um percurso dividido em 43 locais, desde a infância de Darwin na Inglaterra, a viagem no HMS Beagle, dando ênfase no percurso pela América do Sul, até sua morte na Inglaterra, que permite o acompanhamento, passo a passo, do percurso intelectual e geográfico de Charles Darwin para a elaboração da Teoria da Evolução das Espécies. O livro digital tem como meta elucidar os questionamentos e inquietações científicas de Charles Darwin, não somente ao longo da viagem de circum-navegação, mas ao longo de sua vida, enfatizando a influência de grandes pesquisadores, bem como as suas relações com os intelectuais da época, seus conflitos pessoais e o seu amadurecimento científico ao longo dos anos, que resultaram na argumentação e fundamentação de suas ideias para a elaboração da Teoria da Evolução por meio da Seleção Natural. A Figura 2, apresentada a seguir, evidencia a interface principal do livro digital Pelos Caminhos de Darwin: 
Figura 2 - Interface principal do livro digital Pelos caminhos de Darwin

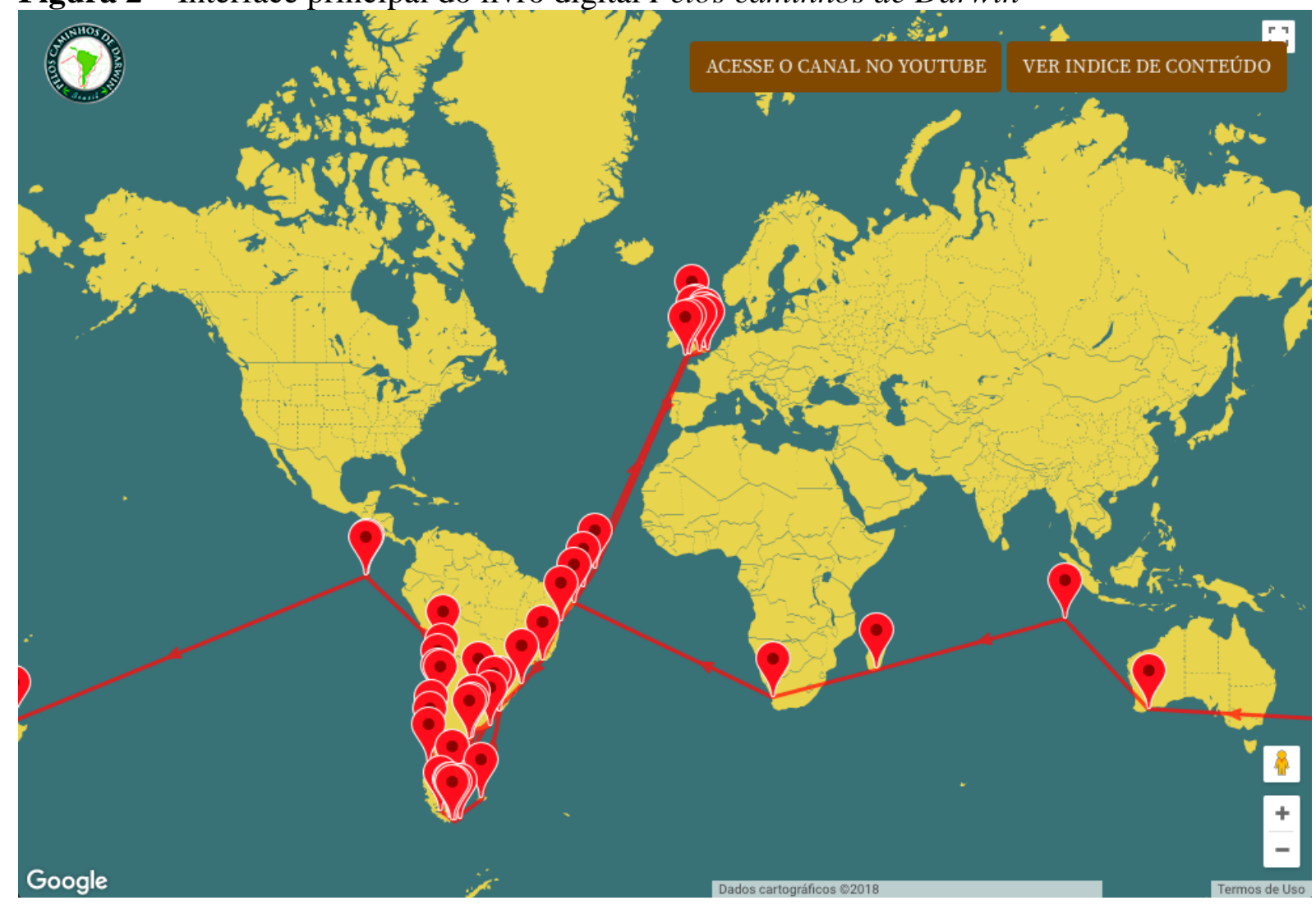

Fonte: Motta et al. (2017a).

Desenvolvido pela equipe do Instituto UFC Virtual, da Universidade Federal do Ceará, esse portal de conteúdos consiste em um dispositivo multimídia que integra diferentes possibilidades de navegação e de interação com o conteúdo e que traz, para o contexto da relação educativa, dinâmicas tecnológicas de construção do conhecimento que, fora da escola, avançam de vento em popa, baseadas em possibilidades hipertextuais e dando forma a dispositivos que demandam interação do sujeito com os conteúdos que lhe são apresentados, a fim de otimizar a experiência do usuário em seu percurso de aprendizagem.

Dentre essas possibilidades, procuramos explorar a plataforma de distribuição digital de vídeos YouTube como dispositivo educativo, a fim de levar o leitor do livro digital a se aproximar de forma mais efetiva dos fenômenos climáticos descritos por Darwin em seu Diário do Beagle. Nessa perspectiva, foi criado um banco de vídeos cuja interface principal é apresentada na Figura 3: 
Figura 3 - Interface principal do canal YouTube Pelos caminhos de Darwin

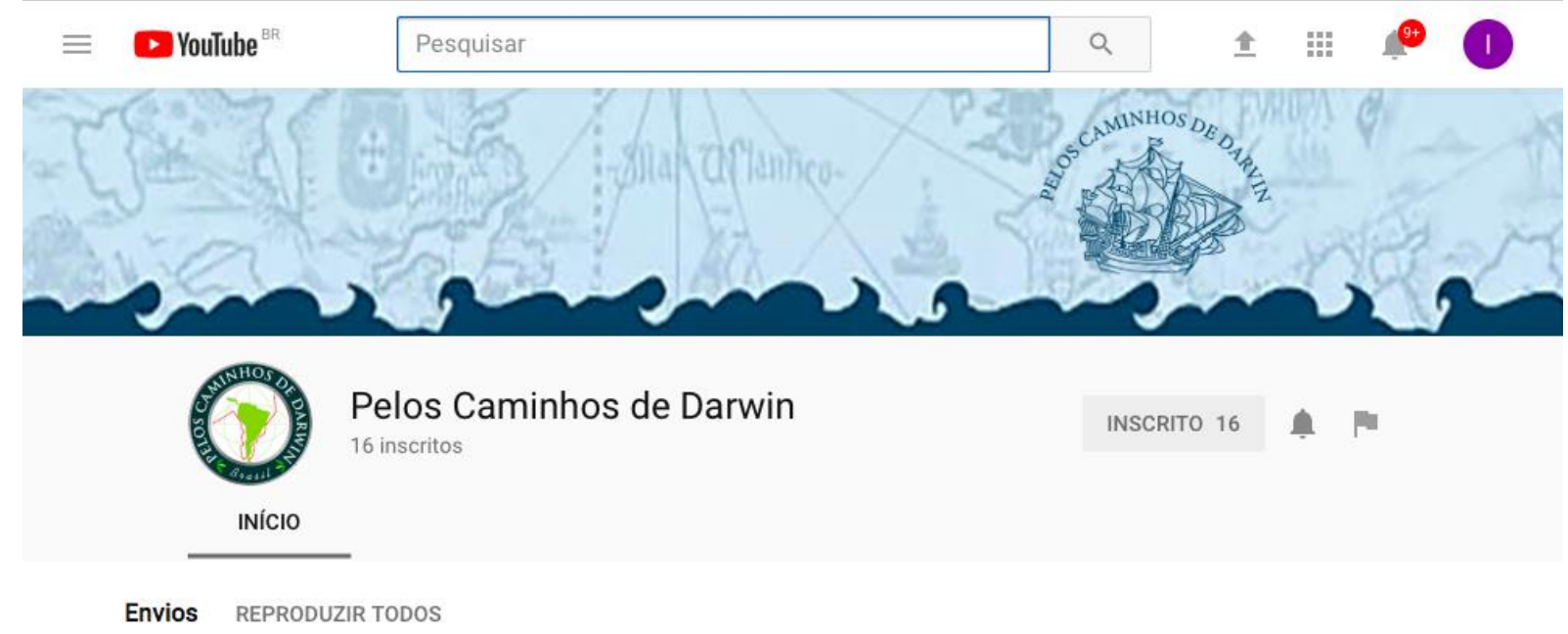

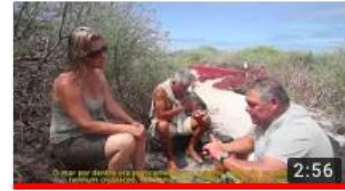

Entrevista Bolívar Pesantez As Consequências Do 18 visualizações . 7 meses atrás

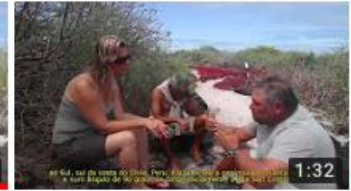

Entrevista Bolivar Pesantez o Clima em Galápagos

9 visualizaçöes $\cdot 7$ meses atrás

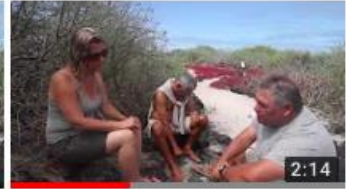

Entrevista Bolívar Pesantez . Fenômeno El Niño

7 visualizaçŏes $\cdot 7$ meses atrás

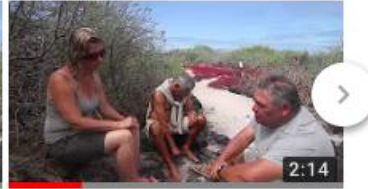

Entrevista Bolívar Pesantez Charles Darwin em 6 visualizaçốes $\cdot 7$ meses atrás

Fonte: Motta et al. (2017a).

Este canal YouTube é composto por 56 vídeos educativos com entrevistas de especialistas, narrações de trechos importantes das observações de Darwin para os locais visitados pela equipe, além da série de nove vídeos intitulada Vivendo o Tempo Atmosférico, elaborada e desenvolvida por Iara Regina Nocentini André, para explicar/exemplificar os fenômenos atmosféricos e as características geográficas presenciadas e registradas por Darwin na obra $O$ diário do Beagle (DARWIN, 2008), de forma dinâmica e lúdica, bem como correlacioná-las com os dias atuais, para o projeto em foco, com o objetivo de dinamizar as interações dos agentes culturais com o livro digital e de gerar aprendizagens significativas.

Distribuídos ao longo da narrativa do livro digital, os vídeos, bem como os demais dispositivos multimídia ali inseridos, criam determinada consistência para o objeto de aprendizagem, a qual o diferencia qualitativamente de um material didático convencional, normalmente caracterizado por uma leitura linear em textos escritos, em suporte papel ou em formato pdf. Enquanto hipertexto, o livro digital, ao contrário, permite diversas navegações, acesso a distintos recursos, diversas possibilidades de abordagem e de construção de narrativas, com o que o conjunto de vídeos é suscetível de contribuir. Mas, podemos considerar isto como um fato? $\mathrm{O}$ acesso a discursos pedagógicos em formato videográfico gera um tipo distinto de interação com os conteúdos? Os vídeos, com imagens fixas e em movimento e com narração 
didática específica para a divulgação científica consiste, efetivamente, em um recurso facilitador do ensino e da aprendizagem? A navegação em um hipertexto, que leva o indivíduo a intercalar textos, fotografias, links diversos e vídeos é elemento gerador de aprendizagens significativas? Os vídeos educativos do projeto Pelos Caminhos de Darwin cumprem seu papel didático de comunicação de conhecimentos geográficos? Quais os limites e as possibilidades de tal recurso pedagógico no ensino da Geografia? Estas foram as questões propostas a um grupo de estudantes de Licenciatura em Pedagogia, futuros responsáveis pelo ensino de Geografia nas séries iniciais do ensino fundamental, inscritos na disciplina Educação, Tecnologias e Comunicação, no Departamento de Métodos e Técnicas da Faculdade de Educação da Universidade de Brasília.

\section{Um breve quadro teórico sobre a exploração pedagógica do YouTube}

O uso de novas mídias mudou nosso cotidiano, principalmente na comunicação, na vivência e no aprendizado. Ferramentas disponíveis na web são utilizadas cada vez mais no ambiente escolar e usá-las como recursos no ensino desperta a curiosidade e estimula os jovens alunos.

Uma dessas ferramentas é o canal YouTube que, quando bem aplicado, além de dinamizar as aulas das diversas áreas, também permite o aprendizado rápido de diferentes conceitos e definições.

Várias pesquisas apontaram o uso favorável desse recurso didático em sala de aula. Schmitt (2015) afirmou que o uso do canal YouTube é uma excelente ferramenta para as práticas didáticas no ensino de Geografia em sala de aula, pois faz parte da vivência dos alunos e promove o interesse e a curiosidade dos jovens.

Para Almeida et al. (2015), novas propostas pedagógicas são necessárias para dinamizar o ensino de Geografia, assim a utilização do YouTube motiva os alunos na obtenção de conhecimento em virtude da dinâmica das imagens e sons, tornando o aprendizado mais eficiente em sala de aula. Contudo, advertem para que o professor seja criterioso na escolha dos vídeos relacionados ao conteúdo programático específico. Vicentini e Domingue (2008) afirmaram que a utilização dos vídeos em sala de aula foi inicialmente uma maneira de dinamizar as aulas, todavia, o uso dessa ferramenta exige planejamento pedagógico para que não seja aplicada de forma equivocada.

Bispo e Barros (2016) ressaltam que o uso de vídeos do YouTube como recursos didáticos somente pode ser efetuado com o planejamento do professor com total domínio do 
conteúdo programático. Ademais, o estudo prévio da realidade dos alunos e do potencial das séries com o intuito de sanar as dificuldades dos jovens no processo de aprendizagem.

Moran (1995) afirma que o uso de vídeos no ensino pode facilitar a introdução de um novo conteúdo, apresentar panorama desconhecido para os jovens, para simular fenômenos e processos específicos, além de motivar e estimular os alunos.

Kamers (2013) realizou uma pesquisa qualitativa com professores e alunos do ensino médio sobre o uso do YouTube no ensino de física e concluiu que essa prática pedagógica educomunicativa é satisfatória.

Segundo Carlsson e Viero (2013), a utilização de recursos audiovisuais no ensino fundamental potencializa o conhecimento e proporciona múltiplas articulações no ensino. Os autores concluíram que os vídeos induzem a interação e a interatividade com o conteúdo proposto, estimulando a curiosidade e a criatividade.

Partindo da premissa que esta prática pedagógica pode ofertar conteúdos que proporcionarão discussões em sala de aula, além de permitir que os alunos se motivem a buscar um aprofundamento nesses conteúdos por este recurso dinâmico, além de auxiliar os jovens que tenham dificuldade de aprendizado, foram avaliados por um grupo de alunos de graduação os vídeos do canal YouTube do projeto Pelos Caminhos de Darwin.

\section{Método, discussão e resultados}

O procedimento de avaliação organizado em torno dos vídeos educativos do projeto Pelos Caminhos de Darwin foi realizado, conforme já indicado, junto a uma turma de Licenciatura em Pedagogia da Faculdade de Educação da Universidade de Brasília, reunindo 43 alunos, no contexto da disciplina Educação, Tecnologias e Comunicação. Com a participação de uma professora de Metodologia do Ensino da Geografia, a turma de futuros pedagogos, que deverão abordar o ensino da Geografia nas séries iniciais do ensino fundamental, navegou pelo livro digital com o objetivo específico de explorar os vídeos educativos nele inseridos. Após a exploração das mídias educativas em sala de aula, os alunos da disciplina avançaram em explorações autônomas para aprofundamentos, ao longo de uma semana. Em seguida, por meio de um grupo especialmente criado com essa finalidade na rede social Facebook, eles foram convidados a responder às cinco questões de avaliação visadas.

Cada questão foi proposta separadamente, sob a forma de "postagens", expressão que designa uma publicação na rede social, a qual demanda respostas qualitativas, sob a forma de comentários. Embora nem todos tenham se manifestado a respeito de todas as questões, 28 
estudantes se manifestaram e emitiram diversos comentários a respeito. É importante enfatizar que todo esse processo acontece de forma pública e coletiva, de modo que os comentários de uns, especialmente dos primeiros alunos que se manifestam, pode influenciar outros comentários que vêm a seguir e gerar debates, posicionamentos concordantes e discordantes. Muitos estudantes manifestam-se apenas por meio de likes, o que significa estar de acordo. Trata-se, portanto, de uma estratégia coletiva e dialogada de avaliação, como uma roda de conversa virtual. Os comentários foram agrupados em indicadores de análise dos vídeos (quadros 1 a 5), as quais são discutidas a seguir.

Quadro 1 - Análise da primeira questão

\begin{tabular}{|l|l|}
\hline $\begin{array}{l}\text { 1 - O acesso a discursos pedagógicos em formato videográfico gera um tipo distinto de interação com os } \\
\text { conteúdos? }\end{array}$ & Número de posicionamentos \\
\hline Indicador de análise & 14 \\
\hline Sim, porque se pode sair do lugar comum do texto corrido & 8 \\
\hline $\begin{array}{l}\text { Sim, porque a imaginação e a criativa do aluno são inseridos no processo } \\
\text { de aprendizagem }\end{array}$ & 10 \\
\hline $\begin{array}{l}\text { Sim, porque há uma riqueza visual nos vídeos que um texto fixo ou uma } \\
\text { fotografia jamais teria }\end{array}$ & 10 \\
\hline $\begin{array}{l}\text { Sim, porque o vídeo ativa zonas específicas do cérebro em processo de } \\
\text { aprendizagem }\end{array}$ & 7 \\
\hline Sim, mas os vídeos mais longos demandam mais atenção e concentração & 23 \\
\hline
\end{tabular}

Fonte: $\mathrm{O}$ autor.

De acordo com os atores envolvidos é possível afirmar que o recurso audiovisual permite sair da prática tradicional do livro didático escrito e estimular o interesse no conhecimento de conteúdos importantes na formação dos alunos. É importante ressaltar que os vídeos bem elaborados/editados com animações, fotos e narração de textos acessíveis para cada nível e modalidade de ensino, atingem a finalidade didática. 
Quadro 2 - Análise da segunda questão

\begin{tabular}{|l|l|}
\hline \multicolumn{2}{|l|}{$\begin{array}{l}\text { 2 Os vídeos, com imagens fixas e em movimento e com narração didática específica para a divulgação } \\
\text { científica consiste, efetivamente, em um recurso facilitador do ensino e da aprendizagem? }\end{array}$} \\
\hline Indicador de análise & Número de posicionamentos \\
\hline Substitui plenamente o professor & 23 \\
\hline $\begin{array}{l}\text { Deve ser um complemento à ação do professor, que dispõe de mais } \\
\text { conteúdos e do contexto geral de tudo }\end{array}$ & 5 \\
\hline $\begin{array}{l}\text { Sim, porque pode ser algo construído pelo próprio professor para } \\
\text { dinamizar suas aulas }\end{array}$ & 17 \\
\hline Os vídeos aguçam a curiosidade e nos levam a pesquisar mais a respeito & 13 \\
\hline $\begin{array}{l}\text { Sim, porque demandam vários sentidos ao mesmo tempo e isso é bom } \\
\text { para se aprender mais e melhor }\end{array}$ & 25 \\
\hline $\begin{array}{l}\text { Muito mais fácil para se ensinar conceitos complexos e muito mais } \\
\text { lúdico e leve para se aprender. }\end{array}$ & 8 \\
\hline
\end{tabular}

Fonte: $\mathrm{O}$ autor.

Segundo os alunos envolvidos, a linguagem utilizada nos vídeos deve ser acessível, apresentando conceitos/conteúdos fáceis ou complexos de forma simples, sem que se perca a essência do objeto em questão, sendo supervisionado pelo professor, que deverá ter domínio do conteúdo apresentado. Os fenômenos ou detalhes são apresentados visualmente, contudo quando os narradores falam e explicam, a entonação dá a emoção, prendendo a atenção do espectador.

Quadro 3- Análise da terceira questão

3 - A navegação em um hipertexto, que leva o indivíduo a intercalar textos, fotografias, links diversos e vídeos é elemento gerador de aprendizagens significativas?

\begin{tabular}{|l|l|}
\hline Indicador de análise & Número de posicionamentos \\
\hline $\begin{array}{l}\text { Sim, porque o entendimento do conteúdo passa a ser mais visual e, } \\
\text { portanto, mais compreensível e efetivo }\end{array}$ & 17 \\
\hline $\begin{array}{l}\text { É sempre bom ter o conteúdo explicado de formas diferentes. Se aprende } \\
\text { mais assim }\end{array}$ & 12 \\
\hline $\begin{array}{l}\text { O hipertexto é mais interessante que o texto porque o texto é muito chato } \\
\text { por ser linear }\end{array}$ & 28 \\
\hline $\begin{array}{l}\text { Um conteúdo todo ensinado por meio de vídeos pode ser chato, mas } \\
\text { inserir vídeos em partes do conteúdo é muito bacana, torna o ensino mais } \\
\text { leve. }\end{array}$ & 13 \\
\hline $\begin{array}{l}\text { É apenas preciso ter cuidado para ninguém se perder e acabar não } \\
\text { aprendendo o que deve ser aprendido. }\end{array}$ & 21 \\
\hline Prefiro aprender lendo ou pesquisando e escrevendo & 2 \\
\hline
\end{tabular}

Fonte: $\mathrm{O}$ autor. 
A maioria dos entrevistados ressaltou que o uso dos hiperlinks evidencia o conteúdo, tornando-o mais fácil de compreensão e facilitando o aprendizado. Contudo, o professor deverá direcionar o conteúdo para que os alunos não se dispersem.

Quadro 4 - Análise da quarta questão

4 - Os vídeos educativos do projeto Pelos Caminhos de Darwin cumprem seu papel didático de comunicação de conhecimentos geográficos?

\begin{tabular}{|l|l|}
\hline Indicador de análise & Número de posicionamentos \\
\hline Alguns vídeos me levaram a observar melhor a natureza & 10 \\
\hline $\begin{array}{l}\text { Se a Geografia fosse sempre ensinada assim, teríamos muito mais } \\
\text { geógrafos }\end{array}$ & 22 \\
\hline $\begin{array}{l}\text { Os vídeos interagem bem com os textos e um chama o outro. É } \\
\text { impossível não gostar e não entender e aprender. }\end{array}$ & 26 \\
\hline $\begin{array}{l}\text { Certamente, muitos conceitos são difíceis de serem compreendidos } \\
\text { apenas pela leitura }\end{array}$ & 13 \\
\hline
\end{tabular}

Fonte: $\mathrm{O}$ autor.

Por unanimidade os entrevistados afirmaram que os vídeos educativos cumpriram o papel de aprendizagem para os conhecimentos em Geografia. Esse recurso audiovisual permite tratar conceitos/definições de forma contextualizada no conteúdo proposto no projeto.

Quadro 5 - Análise da quinta questão

\begin{tabular}{|c|c|}
\hline \multicolumn{2}{|c|}{5 - Quais os limites e as possibilidades de tal recurso pedagógico no ensino da Geografia? } \\
\hline Indicador de análise & Número de posicionamentos \\
\hline $\begin{array}{l}\text { Acho que os vídeos nunca podem ser muito longos e devem dialogar } \\
\text { com os textos }\end{array}$ & 19 \\
\hline $\begin{array}{l}\text { A narração é muito importante para que os vídeos não fiquem chatos } \\
\text { e monótonos }\end{array}$ & 13 \\
\hline $\begin{array}{l}\text { O tipo de vídeo deve respeitar o nível dos alunos. Crianças pequenas } \\
\text { podem preferir animações a vídeos }\end{array}$ & 9 \\
\hline $\begin{array}{l}\text { A principal limitação é a capacidade do professor ser criativo e } \\
\text { desenvolver vídeos e outros materiais bem legais e interessantes }\end{array}$ & 20 \\
\hline
\end{tabular}

Fonte: $\mathrm{O}$ autor.

Os vídeos devem ser trabalhados em sala de aula de acordo com as potencialidades dos alunos nas diferentes séries, buscando sanar as dificuldades de aprendizagem e estimular a criatividade e curiosidade. Para tal, os professores devem dominar o conteúdo proposto e se favorecer deste recurso que pertence ao cotidiano dos alunos. 


\section{Conclusões}

A avaliação dos vídeos pelos atores envolvidos teve uma resposta positiva, demonstrando que este recurso pode ser um aliado no ensino e na aprendizagem, estimulando a curiosidade e criatividade dos jovens estudantes. Nesse caso, especificamente no ensino de Geografia, contudo o uso de vídeos na aprendizagem tem viabilidade em todas as modalidades de ensino e em todos os níveis, desde o Ensino Fundamental ao Ensino Superior, presencial ou não.

Faz-se necessária a inclusão deste recurso no planejamento pedagógico e aproveitar o estímulo dos alunos, desde que sejam selecionados e aplicados intencionalmente para cada conteúdo específico, seja qual for a área de conhecimento, em sala de aula pelos professores. Assim, o uso de tecnologias digitais cotidianas e familiares aos alunos é explorado como ferramenta no planejamento do ensino e da aprendizagem.

\section{Referências}

ALMEIDA, I. D. A.; BEZERRA DA SILVA, J. C.; DA SILVA JUNIOR, S. A.; BORGES, L. M. Tecnologias e Educação: O Uso do YouTube na Sala de Aula. In: CONGRESSO NACIONAL DE EDUCAÇÃO, 2., 2015, Campina Grande. Anais [...]. 2015. Disponível em: http://www.editorarealize.com.br/revistas/conedu/trabalhos/TRABALHO_EV045_MD1_SA4 _ID8097_06092015214629.pdf. Acesso em: 13 dez. 2017.

BISPO, L. M. C.; BARROS, K. C. Vídeos do YouTube como recurso didático para o Ensino de História. Atos de Pesquisa em Educação, Blumenau, v. 11, n. 3, p. 856-868 set./dez. 2016. Disponível em http://dx.doi.org/10.7867/1809-0354.2016v11n3p856-868. Acesso em: 10 dez. 2017.

CARLSSON, F. T.; VIERO, F. O uso de vídeos como recurso pedagógico nas aulas do 4 ano do ensino fundamental, 2013. O Manancial - Repositório Digital da UFSM Santa Maria. Disponível em:

http://repositorio.ufsm.br/bitstream/handle/1/673/Carlsson_Franciele_Tatiane.pdf?sequence= 1. Acesso em: 12 dez. 2017.

DARWIN, C. R. O diário do Beagle. Tradução de Caetano Waldrigues Galindo; revisão e notas de Mareio Renato Guimarães, posfácio Fernando Fernandez. Curitiba: Ed. UFPR, 2008. $526 \mathrm{p}$.

KAMERS, N. J. O YouTube como ferramenta pedagógica no ensino de Física. $177 \mathrm{f}$. Dissertação (Mestrado em Educação, Comunicação e Tecnologia) - Universidade do Estado de Santa Catarina, Florianópolis, 2013. Disponível em: http://www.uniedu.sed.sc.gov.br/wpcontent/uploads/2015/02/nelito_jose_kamers-Mestrado1.pdf. Acesso em: $10 \mathrm{dez} .2017$. 
LACERDA SANTOS, G. Proposta de uma estratégia holística para a engenharia de softwares educativos. Anais do Congresso Anual da Rede Ibero-americana da informática Educativa (RIBIE). 1998. Disponível em:

http://www.ufrgs.br/niee/eventos/RIBIE/1998/pdf/com_pos_dem/208.pdf. Acesso em: 13 dez. 2017.

MORAN, J. M. O vídeo na sala de aula. Revista Comunicação \& Educação, São Paulo: Ed. Moderna, n. 2, p. 27-35, jan./abr. 1995.

MOTTA, C. L. R. da; LACERDA SANTOS, G.; LOEBLER, H.; ANDRÉ, I. R. N.;

BARBOSA, J. P.; PEQUENO, M. C.; HAUFF, S. N. O Diário do Bigou. Brasília, DF: Museu Virtual da Universidade de Brasília, 2017a. Disponível em: http://darwin.museuvirtual.unb.br Acesso em: 13 dez. 2017.

MOTTA, C. L. R. da; LACERDA SANTOS, G.; LOEBLER, H.; ANDRÉ, I. R. N.; BARBOSA, J. P.; PEQUENO, M. C.; HAUFF, S. N. Pelos Caminhos de Darwin. Brasília, DF: Museu Virtual da Universidade de Brasília, 2017b. Disponível em: http://caminhosdedarwin.com. Acesso em: 13 dez. 2017.

SCHMITT, C. M. O YouTube como ferramenta pedagógica no ensino de geografia. $63 \mathrm{f}$. Monografia (Especialização em Mídias na Educação) - Universidade Federal do Rio Grande do Sul, Porto Alegre, 2015. Disponível em:

https://www.lume.ufrgs.br/bitstream/handle/10183/133982/000978838.pdf?sequence=1. Acesso em: 10 dez. 2017.

VICENTINI, G. W.; DOMINGUE, M. J. C. S. O uso do vídeo como instrumento didático em sala de aula. Curitiba, 2008. Disponível

em: http://home.furb.br/mariadomingues/site/publicacoes/2008/eventos/evento-2008-09.pdf. Acesso em: 12 dez. 2017. 